\title{
A new vision for the old bazaar street and surroundings in Koya city
}

\author{
Zh. B. Ahmed \\ Department of Architectural Engineering, Koya University, \\ Kurdistan Region, Iraq
}

\begin{abstract}
During the past years Koya city has faced a regression in urban development and this in turn has caused many problems in the urban configuration such as unplanned urban growth, traffic problems increased, neglected heritage and a preliminary type of living with limited options for modern life style requirements. This paper demonstrates these problems and suggests a proposal that shows the potentials of the city. It demonstrates how heritage zones could be successfully redeveloped and enhanced without losing its significant character and mix of activities. Koya bazaar is an excellent example of such heritage zones and it needs to be valued and considered by the local government by taking a pragmatic approach to the future of the area, regarding the need to a wide study, new building regulations, and extensive public consultation and participation in this process. The focus of the process is on managing the change without deforming this zone's character.

Keywords: Koya, heritage, urban development, sustainability, tourism, old city.
\end{abstract}

\section{Introduction}

In this case study, the area of the old bazaar of Koya city is studied, since it is considered as the focal point of Koya city, but its cultural value and heritage is still neglected, so this study works on enhancing the value of this area which in turn will affect the surrounding areas as well. First of all, a survey was made to know the existing problems in the area and hear people's opinion in order to understand their problems and estimate their ability of accepting any change or development in the area. The change must be in a way that could be acceptable by the people living there and the urban context so a general policy 
would be taken place to perform general improvements. This area contains an old bazaar which is quite neglected, other shops, a historical place called the Khan, a mosque that also has a historical value, and some old residential units which some of them have a historical value as well. So the main policy is to give a traditional form to this area, as in cities like Koya, culture and traditions can be regarded as a treasure by which we can attract tourists, so that the area will be revitalized again.

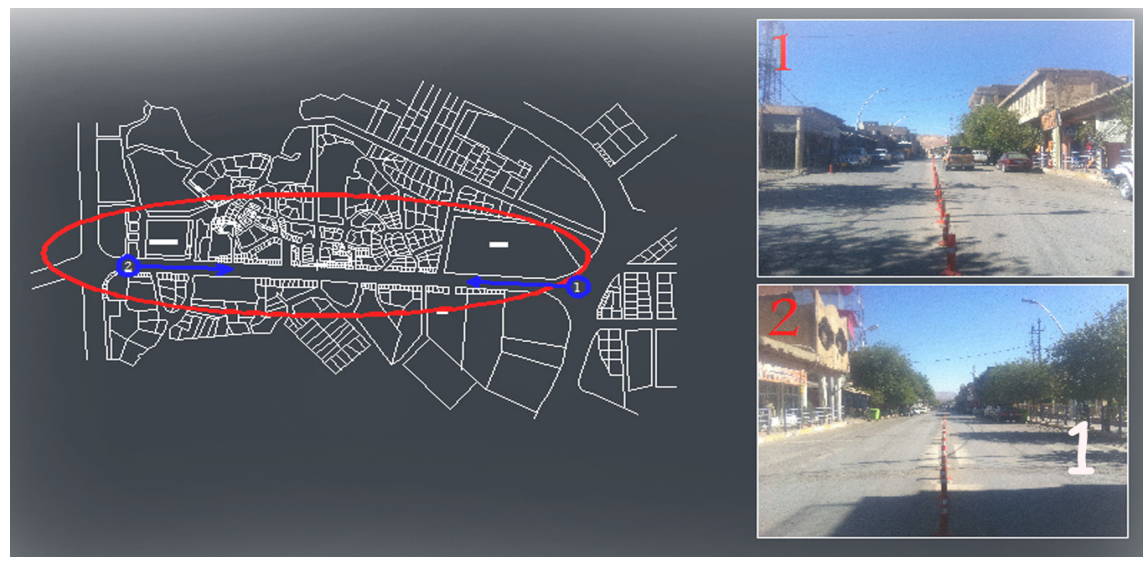

Figure 1: $\quad$ Location of case-study [1, 2].

\section{Studying the area}

First of all, a survey was made to observe the area, indicating the main functions in the area (land use), building condition, and what kind of materials is generally used. From this survey, the information about the area was gained and the positive and negative sides of the area became clearer.

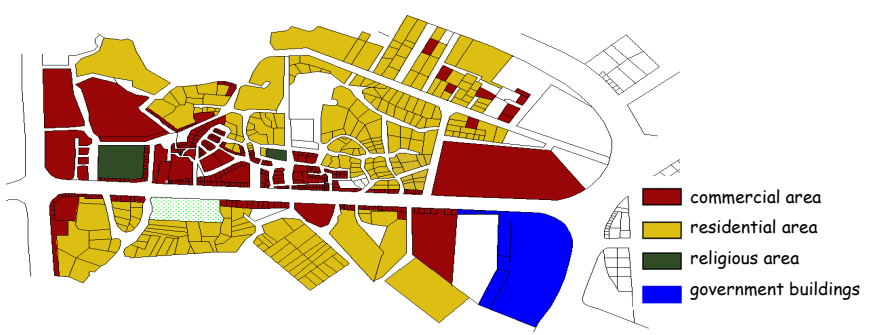

Figure 2: $\quad$ Land use plan in the area [2]. 


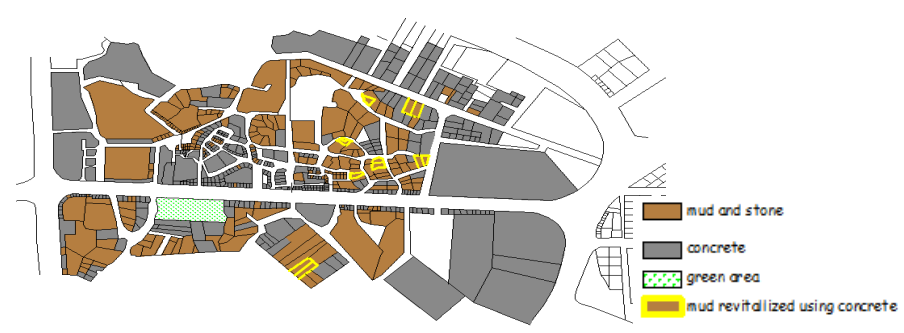

Figure 3: $\quad$ Building materials plan in the area [2].

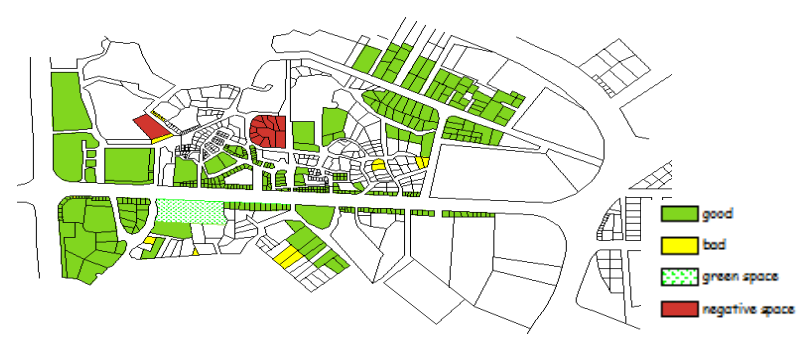

Figure 4: $\quad$ Buildings physical condition in the area [2].

\subsection{Problems in the area}

Generally, the main existing problem is the lack of organization and the chaos seen in the urban context, and here are some of the critical problems: primary form of living style in Koya that leads to immigration to obtain more options; the absence of a logical urban design; no harmony in elevations and the skyline; contemporary used materials do not belong to the identity of the city heritage; lack of needed green area and open spaces in the area; lack of places for
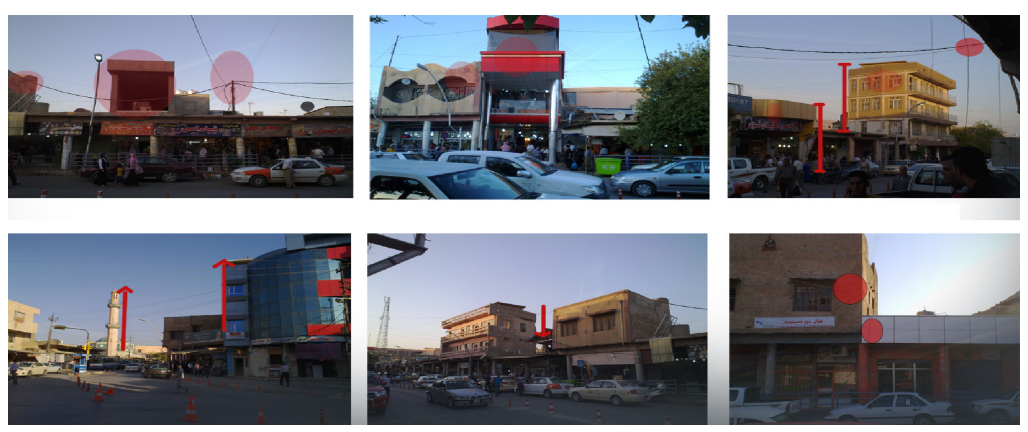

Figure 5: Lack of harmony, unity, continuity, and rhythm in urban context [1]. 
entertainment activities; traffic problems; and unreasonable mix between some of the old residential units with the industrial functions which affect the social life in those areas. For further details read [3].

\section{The proposal}

Encouraging tourism by projects and activities that attract tourists; providing commercial functions to change the area into a commercial one, which in turn increase the opportunity of work and provide jobs to the citizens; rehabilitation of the places that have historical values and using them to attract tourism and preserve the cultural character of the city; maintaining and fixing the infrastructure; adding new interesting activities and functions in the area; controlling the new buildings by providing strict regulations that could keep the urban context of the old city in balance; and organizing the movement of pedestrian and vehicles. All the above are some of the urgent requirements of the old city and especially within the case study area, and need to be considered in new proposals, the following is a proposal with a new vision for the city.

\subsection{Re-arrangement of the urban configuration}

The urban configuration is re-arranged allover as shown in the plan below (figure 6), a part of the old fabric is remained as it was before adding new residential units to the areas where social life is more suitable, and focusing on the commercial areas.

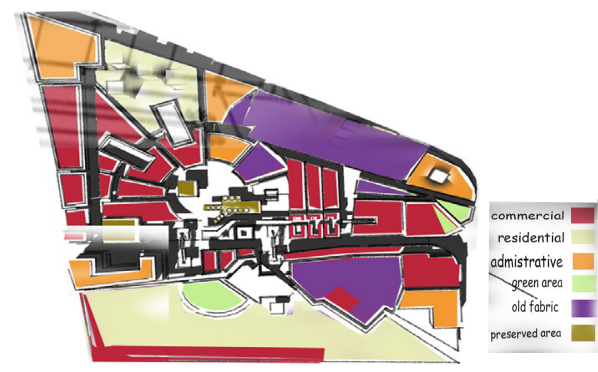

Figure 6: Plan of the new proposed configuration [1].

\subsection{Sustainable concepts in the area}

Nowadays sustainability is the main means and procedures to provide a healthy enjoyable environment. There are many ideas for achieving sustainability but the most important is the way of making them compatible with the urban context, suitable for the land use, and acceptable to the observer. 


\subsubsection{Encouraging pedestrian movement}

One of the most important procedures to be considered is preventing vehicles from accessing the main street of the bazaar, as that would reduce traffic jams, encourage people to walk and enjoy the view, as well as providing a healthier environment and enhances the activities around the area. For further details read $[3,4]$.

\subsubsection{Providing comfort and saving energy}

However, to enhance pedestrian movement, that would require a comfortable environment. We can provide this comfort by preventing the sharp sunlight from affecting negatively on human energy by adding distributed sustainable umbrellas over the main street that provide shade, save energy and re-use it at night to provide lighting for the street. Furthermore, many more interesting activities could be located on the main street to attract people. For further details read [4].

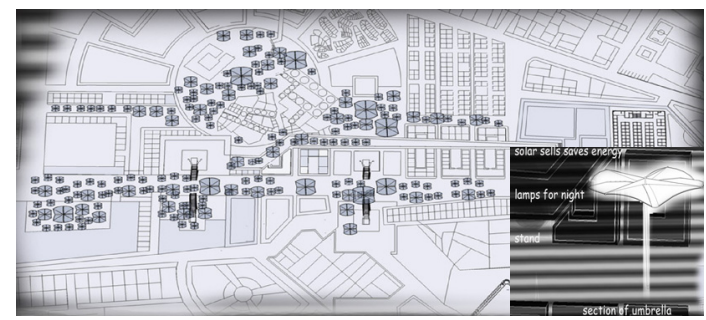

Figure 7: Distribution of umbrellas over the area and type of umbrella [1].

\subsubsection{Open spaces and green areas}

More open spaces and green areas are required in the area to provide a healthy enjoyable environment, and for other planning purposes. For example making a cluster of some important buildings within the urban configuration, a good place for the proposed cluster, is on the main street exactly where the location of Malai Gawra mosque to avoid the boring continuality of the main street, give a dominant character to that place which will be observed easily as it has the mosque and the main gate of the old Qaisariah, and provide more interesting activities in that zone [1] (Figure 8).
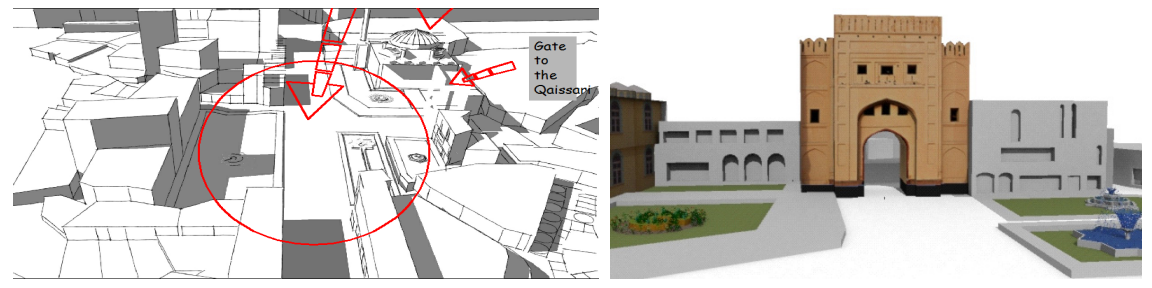

Figure 8: A cluster in the urban configuration and Qaissariah's gates proposal [1]. 


\subsection{D conversation with the context}

In addition to 2D planning; urban design should consider also the skyline of the urban scene and work with it from the $3 \mathrm{D}$ aspects. While studying the location, common errors were found within the urban scene and skyline as shown in (figure 9) and therefore the proposals of the new elevations (figure 10) consider the skyline, heights of buildings, as well as the form of the buildings and organize them in a more acceptable way that provide a better urban scene. For further details read [3].

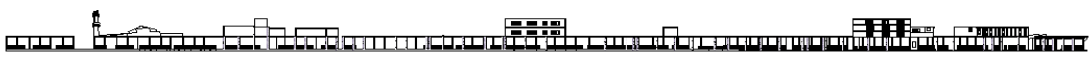

Figure 9: $\quad$ The current elevation of the main street [1].

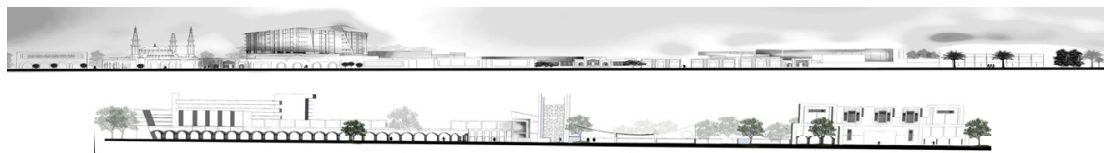

Figure 10: $\quad$ Elevation proposals for both sides [1].

\section{Conclusion}

Urban renovation and development are important procedures that need the following strategy to be successful; the first step is to determine the main goal of the whole project, then state clearly the existing problems, study them thoroughly, and finally, find the proper solutions that are suitable with the multiaspects of the city according to specific criteria that should be announced. This proposal provides a new vision of the city, according to a general strategy that needs to be performed efficiently more extensive studies to determine the right performance and the further detailed procedures. It is crucial for such studies to educate the citizens and make them aware of the whole process, and offer them chances to participate in the renovation process through various meetings that make them a part of the making-decisions-process. Heritage is a sensitive moral issue that could give the city its own cultural identity. It requires a wide study for city's history, architectural details; and in the meantime, needs a future vision.

\section{References}

[1] Author in her field study, design class (4th year) 2011-2012.

[2] Municipality of Koya city, Koya city, 2011-2012.

[3] Lynch, Kevin, The Image of the City, MIT Press, Cambridge MA 1960.

[4] Dezeen - architecture and design magazine, London, 2006-2012. 